\title{
AS CLÁUSULAS PÉTREAS E NORMA DE (IN) COMPETÊNCIA OU UMA HISTÓRIA DE ULISSES E AS SEREIAS
}

\author{
THE IMMUTABLE CLAUSES AND THE NORM OF (IN) COMPETENCE OR A STORY OF \\ ULYSSES AND THE SIRENS
}

Valterlei A. da Costa

Mestrando em Direito do Estado e Bacharel em Direito pela UFPR. Ex-Técnico de Finanças e Controle da Procuradoria da Fazenda Nacional. Advogado em Curitiba/PR

E-mail: costa.valterlei@gmail.com

Recebido em: 11/09/2018

Aprovado em: 07/04/2021

RESUMO: A Constituição de 1988 permite expressamente ser emendada. Trata-se de norma de competência. E a norma de competência, como qualquer outra norma, para ser completa, é formada de duas partes. A primeira traz que certa conduta, a de pôr a emenda, é permitida se presente ou se ausente dada circunstância. A segunda prescreve que não sendo a emenda posta segundo a forma estabelecida, então deve-ser uma conduta de garantia para invalidar, no caso, declarar inconstitucional, essa emenda. Dados esses pontos, os quais serão alcançados por uma metodologia do tipo descritiva, elaborados com base em pesquisa bibliográfica, o objetivo é analisar as cláusulas pétreas calcado nessa teoria normativa, haja vista que vem sendo o tema desenvolvido de forma independente, desconectado de qualquer sintaxe jurídica, o que aqui se identifica como o problema que motiva o presente estudo. E tudo para concluir, via método hipotético-dedutivo, que as cláusulas pétreas são fragmentos, ou seja, normas jurídicas não-autônomas, as quais saturam o conteúdo da consequência da primeira parte da norma de competência, estabelecendo limitações de conduta.

Palavras-chave: Norma jurídica. Norma de competência. Emenda à Constituição. Cláusulas pétreas.

ABSTRACT: The Constitution of 1988 expressly allows to be amended. It is the norm of competence. And the norm of competence, like any other norm, to be complete, is formed of two parts. The first is that certain conduct, in case, the conduct of to put the amendment, is permitted if present or absent given circumstance. The second part prescribes that not being the amendment put into the established form, then should be a conduct of warranty to invalidate, in case, declare unconstitutional, the amendment put. Given these points, which will be achieved by a descriptive methodology, based on bibliographic research, the objective is to analyze the immutable clauses, based on this normative theory, in view of the fact that the theme has been treated of independent manner, disconnected from any legal syntax, which is identified here as the problem that motivates the present study. And everything to conclude, through the hypothetical-deductive method, that the immutable clauses are fragments, that is, dependent legal norms, that saturate the content of the 
consequence of the first part of the norm of competence, establishing negative limitations of conduct.

Keywords: Legal norm. Norm of competence. Constitutional amendment. Immutable clauses.

SUMÁRIO: Introdução. 1 Ulisses e as Sereias. 2 Lex posterior derogat legi priori. 3 Texto e norma. 4 Norma jurídica. 5 Homogeneidade sintática das normas jurídicas. 6 Norma e sanção. 7 Norma primária e norma eventual. 8 Norma de conduta e norma de competência. 9 Emenda constitucional: desambiguação. 10 As cláusulas pétreas e a norma de (in) competência. Conclusão. Referências Bibliográficas.

\section{INTRODUÇÃO}

Nestes quase 30 anos de Constituição, já advieram 99 emendas a ela, isso sem contar as seis emendas de revisão que seguiram forma própria de tramitação. Com isso, por um lado, sempre podemos afirmar que a democracia é algo em permanente construção, mas, por outro, não podemos esquecer que um mínimo de previsibilidade faz parte de qualquer ideia de democracia. Tanto assim é que nossa Constituição estabeleceu como forma de alteração de seus dispositivos um processo mais complexo do que aquele para as demais alterações de legislação. Ademais, não se limitou a criar dificuldades, proibindo expressamente a alteração: da forma federativa do Estado; do voto direito, secreto, universal e periódico; da separação dos Poderes; e dos direitos e garantias individuais. E não só isso. Com sentido de ênfase, proibiu a própria deliberação de emenda nesses casos, e, ainda, quanto ao conteúdo da proposta de emenda, abrangeu inclusive a mera tendência a abolir.

Há, evidentemente, um descompasso. Na forma primária, a Constituição não só dificultou sua alteração, como foi além, proibindo mesmo a deliberação de uma proposta que tenha tendência a abolir determinados pontos tidos por chaves. Na aplicação dessa regra, entretanto, não se logrou o intento, pois são quase 100 o número de emendas à Constituição. Número que não foi alcançado ainda porque, enquanto se escreve este artigo, a União promove intervenção no Estado do Rio de Janeiro, o que impede o dimanar de qualquer emenda.

Não se pretende aqui discutir as razões dessa fúria legiferante reformista; se, de fato, a versão originária da Constituição mereceria tantas emendas. Todavia, vemos a necessidade de um enfoque sobre num ponto específico, qual seja, aquele ao qual se chama comumente de cláusulas pétreas, haja vista que são elas, em nosso entender, estudadas de forma segmentada, problema que conduz a este artigo, sem uma compreensão da posição que ocupam dentro da estrutura normativa. Discorreremos, então, como objetivo deste trabalho, sobre como as várias proibições de emenda se ligam ao processo reformador, e, para tanto, a modalidade de pesquisa realizada será a bibliográfica, que nos fornecerá a base para localizar o tema a partir da teoria da norma jurídica, tipo de pesquisa descritivo, quando, por fim, apresentaremos nossa conclusão — qual seja, que são as cláusulas pétreas fragmentos de norma jurídica —, ancorada no método hipotético-dedutivo.

\section{ULISSES E AS SEREIAS}

Em sua volta para casa, concluída a guerra de Tróia, em sua Odisseia, Ulisses, ao passar pela costa da Ilha das Sereias, determinou que fosse amarrado ao mastro de seu navio, “[...] dando instruções a seus homens para não libertá-lo, fosse o que fosse que dissesse ou fizesse [...]"1. Assim ordenou: "mantenham-me amarrado até passarmos pelo território das Sereias". Ordem que valeu, mas já a outra ordem — desamarrem-me agora —, dada enquanto passavam pelo campo dos

\footnotetext{
${ }^{1}$ Thomas Bulfinch, O livro de ouro da mitologia: história de deuses e heróis, p. 289 (XXIX). Entre parênteses, fazemos referência ao capítulo, seção ou parte em que a citação se encontra na obra.

Revista de Direito Brasileira | Florianópolis, SC | v. 28 | n. 11 | p.16-33 | Jan./Abr. 2021
} 
encantos, não valeu. Poderia se ver nisso uma espécie de autolimitação. O homem de hoje restringe o homem do amanhã. As razões para essa circunscrição podem ser as mais variadas. De forma jocosa, pode mesmo dizer-se que é o sóbrio criando limitações para quando estiver bêbado. Palavreado que, na verdade, pode mais ocultar do que ajudar ${ }^{2}$. Afinal, "[...] transferir conceitos usados para estudar indivíduos para o comportamento de coletividades, como se estas fossem indivíduos em escala ampliada, pode ser enganosa" 3 . De todo modo, não é exatamente um caso de autorrestrição a situação de Ulisses. Ao menos, não diretamente.

Se alguém, de forma deliberada, retira os meios físicos para que não possa, no futuro, mesmo que próximo, praticar (ou omitir) certa conduta, então, em sentido estrito, estamos diante de uma autorrestrição. É perfeitamente o caso do pródigo que sai de casa sem dinheiro, ou com pouco, para que não tenha a opção de gastar. Claro que sempre é possível voltar para casa e buscar a carteira, o que dá ensejo a ideia de que quem se amarra, de algum modo, pode desamarrar-se. Essa, entretanto, não é a situação de Ulisses. Há uma primeira ordem: "amarrem-me". Ordem essa dirigida a terceiros, os marinheiros. Há uma segunda ordem: "desamarrem-me". Também dirigida aos marinheiros. E entre essas duas ordens, há uma outra: "até passarmos a costa da Ilha das Sereias, não devo ser desamarrado nem que assim eu ordene”. Ordem essa, igualmente, dirigida aos marinheiros.

Ulisses regula a conduta de terceiros, dos marinheiros, e não a sua própria. Apenas indiretamente é que sua conduta é limitada. A ideia de autolimitação é assim apenas uma ilustração, algo que "[...] deve impressionar vivamente a imaginação para impor-se à atenção"4. $\mathrm{O}$ entendimento com fins poéticos, ou de agrado estético ou ideológico, ou, ainda, de autoilusão, pode resultar na compreensão de serem as cláusulas pétreas autolimitações, espécie de précompromissos. Mas, na verdade, conforme adiante se demonstrará, são regulamentação da conduta de terceiros, impedindo, nos casos especificados, que a ordem dada por último prevaleça sobre a ordem dada primeiro.

\section{LEX POSTERIOR DEROGAT LEGI PRIORI}

Dá-se um texto $\mathrm{T}_{1}$, do qual se tem a norma $\mathrm{N}_{1}$. Norma essa que prescreve ao sujeito $\mathrm{S}$ o dever de conduta $q$, desde que antes tenha sido $p$. Dá-se, também, um texto $\mathrm{T}_{2}$ e dele obtém-se a norma $\mathrm{N}_{2}$. Norma que, por sua vez, prescreve ao mesmo sujeito $\mathrm{S}$ que se $p$, então deve-ser a conduta $\sim q$. Diante dessas duas normas, pergunta-se: o que se pode inferir diante da ocorrência de $p$ ? Nada além de que "[t]em alguém [no nosso caso $\mathrm{S}$ ] que escolher qual das duas normas há de observar e, por conseguinte, qual das duas quer infringir. Mas não possui esse alguém o poder de fazer cessar a validade da norma a que não quer obedecer" 5 . Assim, por meio da razão, não há a possibilidade de se encontrar uma solução para a contradição, pois de um ser, não deriva um dever-ser ${ }^{6}$. Apenas

\footnotetext{
2 "The expression an 'appeal from the people drunk to the people sober', which is often used in this connection, stresses only one aspect of a much wider problem and, by the levity of its phrasing, has probably done more to veil than to clarify the very important issues involved". Friedrich A. Hayek, The constitution of liberty, p. 180 (12). Livremente: “A expressão 'apelo dos bêbados aos sóbrios', que é frequentemente usada nesse sentido, enfatiza apenas um aspecto de um problema muito mais amplo e, pela frivolidade da frase, provavelmente fez mais para encobrir do que para esclarecer as questões muito importantes envolvidas".

${ }^{3}$ Jon Elster, Ulisses liberto: estudo sobre racionalidade, pré-compromisso e restrições, p. 124 (2.2).

${ }^{4}$ Chaïm Perelman e Lucie Olbrechts-Tyteca, Tratado da argumentação: a nova retórica, p. 407 (79).

${ }^{5}$ Hans Kelsen, Manuscrito Direito e Lógica (9.6.1965), In: Hans Kelsen e Ulrich Klug, Normas jurídicas e análise lógica: correspondência trocada entre os Srs. Hans Kelsen e Ulrich Klug, p. 66.

${ }^{6}$ É conhecida por lei de Hume a impossibilidade de se deduzir o que deve-ser do que é: "Em todo sistema de moral que até hoje encontrei, sempre notei que o autor segue durante algum tempo o modo comum de raciocinar, estabelecendo a existência de Deus, ou fazendo observações a respeito dos assuntos humanos, quando, de repente, surpreendo-me ao ver que, em vez das cópulas proposicionais usuais, como é e não é, não encontro uma só proposição que não seja conectada a outra por um deve ou não deve. Essa mudança é imperceptível, porém da maior importância. Pois, como esse deve ou não deve expressa uma nova relação ou afirmação, esta precisaria ser notada e explicada; ao Revista de Direito Brasileira | Florianópolis, SC | v. 28 | n. 11 | p.16-33 | Jan./Abr. 2021
} 
por um ato de vontade, e não de razão, que põe um texto $T_{3}$, do qual se obtém uma norma $\mathrm{N}_{3}$, é que pode solucionar-se o conflito. E um conteúdo possível de $\mathrm{T}_{3}$ é que entre $\mathrm{T}_{1}$ e $\mathrm{T}_{2}$, vale, ou seja, é capaz ensejar norma válida, aquele posto, ou seja, positivado, por último.

Não vamos aqui discutir porque ideais tais como "a última vontade é a que vale" são, para nós, "óbvias/intuitivas". Provavelmente por estamos acostumados com tais pensamentos, achamos que sempre estiveram lá, pois “[...] após uma repetição de casos semelhantes, a mente é levada pelo hábito, quando um dos acontecimentos tem lugar, a esperar seu acompanhante habitual e a acreditar que ele existirá" 7 . O certo é que antes do texto $\mathrm{T}_{3}$, tanto eram devidas, pelo sujeito $\mathrm{S}$, na presenta de $p$, a conduta $q$ como a $\sim q$. Agora, com a presença da norma $\mathrm{N}_{3}$, obtida do texto $\mathrm{T}_{3}$, texto posto e não pressuposto nem intuído, a que comumente nos referimos pelo brocardo latino lex posterior derogat legi priori, não há mais contradição, bastando verificar qual texto foi posto por último, se $\mathrm{T}_{1}$ ou $\mathrm{T}_{2}$, e, a depender da resposta, deparar-se com uma única norma válida, ou $\mathrm{N}_{1}$ ou $\mathrm{N}_{2}$.

Se voltarmos, agora, ao caso de Ulisses, há dois suportes físicos, não textos, mas manifestações verbais, dos quais se obtém duas normas contraditórias: uma, marinheiros não me desamarrem; outra, marinheiros me desamarrem. Ocorre que, nesse exemplo, não há nenhuma norma $\mathrm{N}_{3}$ que determine como válida a norma obtida a partir da última expressão, e, assim, passou o grande herói incólume pelas sereias. Devemos, portanto, investigar outros modos de solução de conflitos que não o clássico "lei posterior revoga lei anterior".

\section{TEXTO E NORMA}

Um texto é uma produção humana, algo posto. Mas é algo que está por outra coisa. Não é meramente tinta num papel. Ocorre que para sabermos o que é essa outra coisa, devemos interpretá-lo. E dessa interpretação pode resultar uma regulação de conduta humana, da qual "[...] unas son obligatorias, otras prohibidas, otras facultativas" 8 . Se nos prendermos às lições de SAUSSURE, para quem signo é uma função que une significado e significante ${ }^{9}$, a norma seria o significado que advém do significante, o texto. Texto e norma, expressão e conteúdo, são, por essa linha, unidos pela função semiótica. Ou seja, “[...] expressão e conteúdo são solidários e um pressupõe ao outro" $"$.

Mas, para uma devida compreensão do assunto, isso não basta; devemos introduzir um novo conceito: o de significação. Um signo, no seu sentido bivalente, significante-significado, pode não trazer nenhuma mensagem. Haveria, na maioria das vezes, a necessidade de vários termos, unidos por constantes, para tanto. Por essa trilha, "[a] significação pode ser concebida como um processo; é o ato que une o significante e o significado, ato cujo produto é o signo" ${ }^{11}$. Não se está preso, assim, a um único significante e a seu significado. A mensagem geralmente é feita com vários significantes, do qual a sua significação não é meramente a soma dos significados. Assim,

[...] o significado não tem por si mesmo unidade alguma: a mesma fatia de significação pode ser expressa seja pelo significante único prefeito, seja pela

mesmo tempo, seria preciso que se desse uma razão para algo que parece inteiramente inconcebível, ou seja, como essa nova relação pode ser deduzida de outras inteiramente diferentes". David Hume, Tratado da natureza humana, p. 509 (III.I.I.27) (itálicos constam do original).

${ }^{7}$ David Hume, Investigações sobre o entendimento humana e sobre os princípios da moral, p. 113 (7).

${ }^{8}$ Ricardo A. Guibourg, El fenómeno normativo: acción, norma y sistema, la revolución informática, niveles del análisis jurídico, p. 66 (II.3).

9 “Chamamos signo a combinação do conceito e da imagem acústica [...]. [...]. Propomo-nos a conservar o termo signo para designar o total, e a substituição conceito e imagem acústica respectivamente por significado e significante; estes dois termos têm a vantagem de assinalar a oposição que os separa, quer entre si, quer do total de que fazem parte". Ferdinand de Saussure, Curso de lingüística geral, p. 81 (I.I.1) (itálicos constam do original).

${ }^{10}$ Louis Hjelmslev, Prolegômenos a uma teoria da linguagem, p. 54 (13).

${ }^{11}$ Roland Barthes, Elementos de Semiologia, p. 51 (II.4) (itálico consta do original). 
combinação administrador civil de uma cidade; no primeiro caso temos um significado único, e, no segundo, uma série de significados; é a unidade do significante que determina a unidade do significado. Impõe-se, pois considerar o signo como uma associação de direção única: o significante é o meio de atingirmos o significado ${ }^{12}$.

Num texto, temos vários significantes, que, por sua vez, correspondem a vários significados. Mas isso ainda não é a norma. A norma é a significação, o resultado alcançado pelo intérprete em sequência à análise de todos os significantes e correspondentes significados, que nem mesmo podem estar todos em um único documento. Com efeito, "[s]ignificação é o efeito produzido pelo signo sobre o intérprete em condições que permitissem ao signo exercitar seu efeito total [...]"13 . Logo, quando se está diante de uma interpretação parcial, não há, ainda, de se falar em norma, pois ausente a significação. Na verdade, a norma surge da conjugação de dispositivos textuais. A norma é, por essa linha, significação. De nada vale garimpar significantes específicos, e se deleitando com seus significados, se, ao fïm do processo, o que interessa é a norma na acepção de significação. Esses processos parciais só interessam enquanto meio para o resultado final, mas não têm valores por si só. Tratá-los autonomamente somente pode levar a equívocos quanto à significação da norma.

No mais, basta lembrarmos do que a lógica chama de intensão e extensão. Para a extensão, sua definição consiste, "[...] simplesmente, em indicar os objetos a que o termo se aplique" ${ }^{14}$. Um exemplo seria $\{0,2,6,8$ e 10$\}$. Assim, o texto pode trazer todos os casos que, se ocorridos, ensejam o dever de conduta. Já na segunda situação, da intensão, a definição dá-se como a "[...] propriedade comum de todos os seus membros [...]"15. Para o mesmo exemplo, teríamos: os números naturais pares até o dez-inclusive, com a não-inclusão do quatro. Ambas as definições apresentam a mesma significação. Não há motivos para darmos à expressão "não-inclusão do quatro" um caráter independente. Assim, não se deve imaginar as exceções como normas próprias. O objeto é a conduta prescrita, e em razão do porquê ela é devida, tomada aqui exclusivamente como realização da hipótese normativa, e isso só se alcança com a análise de todos os significantes e seus respectivos significados.

Com isso, à guisa de arremate parcial, podemos concluir que norma é a significação produzida pelo intérprete ao fim do processo; as exceções, por sua vez, nas palavras de LARENZ, não devem ser lidas de modo autônomo, já que "[a]s proposições jurídicas restritivas contêm uma ordenação negativa de vigência (<<não vigora >>) que só se torna compreensível em conjugação com uma ordenação positiva de vigência precedente"16.

\section{NORMA JURÍDICA}

Do texto, temos norma, mas ainda não sabemos se temos norma jurídica válida. E nem podemos saber. Não há nada intrínseco em um texto, ou melhor dizendo, em seu conteúdo, que permita concluir que dele se deve obter norma jurídica válida. Na verdade, apenas na presença de uma outra norma, que seja ela mesma uma norma jurídica, produto, por sua vez, de outro texto, é que é possível averiguar se o texto em questão é fonte de direito. Em suma, "[a] norma que empresta ao ato o significado de um ato jurídico (ou antijurídico) é ela própria produzida por um ato jurídico, que, por seu turno, recebe a sua significação jurídica de uma outra norma" ${ }^{17}$.

\footnotetext{
${ }^{12}$ Eric Buyssens, Semiologia e comunicação lingüística, p. 80 (V.1).

${ }^{13}$ J. Teixeira Coelho Netto, Semiótica, informação e comunicação, p. 72 (A.2.5) (itálico consta do original).

${ }^{14}$ Leonidas Hegenberg, Dicionário de lógica, verbete "extensão", p. 80.

${ }^{15}$ Nicola Abbagnano, Dicionário de filosofia, verbete "classe", p. 146.

${ }^{16}$ Karl Larenz, Metodologia da ciência do direito, p. 363 (II.II.2.b).

${ }^{17}$ Hans Kelsen, Teoria pura do direito, p. 4 (I.4).
} 
Um texto é fonte de norma jurídica se há outra norma jurídica que assim estabeleça. Mas essa norma criadora é fruto, de igual modo, de um texto que só pode ser nascente se também sobre ele dispuser outra norma jurídica. Como não há norma jurídica que não advenha de texto ${ }^{18}$, e se sabemos que o texto per se não é fonte de norma jurídica, careceremos sempre de norma jurídica prévia, o que nos leva a um impasse, já que estaríamos frente a um regresso ad infinitum.

A norma jurídica é posta por um fato que, por sua vez, só é dador de tal norma jurídica porque há uma outra norma jurídica que assim dispõe. Essa norma jurídica que estabelece que certo fato é fonte do direito, por sua vez, também é posta por outro fato. Pode-se ir, então, regredindo, mas quando se chega ao texto constitucional, produto do fato fundamental, não há mais para onde ir.

O texto constitucional é uma criação humana e não uma revelação. É a partir dele que se obtém as normas constitucionais, as quais, numa visão hierarquizada, piramidal, são as mais importantes. Entretanto, o texto constitucional também é posto, o que faz desse pôr um fato, o fato fundamental, o qual "[...] requer outra norma pressuposta para juridicizá-lo, para tornar-se fato jurídico e dar começo lógico à continuidade normativa no interior do sistema" ${ }^{19}$. Estamos, com isso, diante de um ser que cria um dever-ser, e caso não se queira transgredir a lei de Hume, já exposta, então há a necessidade de se pressupor uma norma, a norma fundamental.

Não queremos, neste ponto, descarrilar a discussão, mudando o foco do artigo para a norma fundamental ${ }^{20}$. De certo, vamos dá-la como aceita, nos moldes kelsenianos. Afinal, “[...] mesmo os princípios cuja certeza não é completa podem ter a sua utilidade, se sobre eles construirmos apenas para efeito de demonstração" 21 . Assim, "[1] norma fundamental no es una norma impuesta, sino presupuesta como condición de todo el conjunto de la creación jurídica, de todo procedimiento positivo" 22 . É ela, com efeito, o fecho do sistema, pois de uma multiplicidade de normas jurídicas, podemos reduzir todas a uma só origem. Temos, ao menos do ponto de vista da unicidade, um sistema ${ }^{23}$. E, "[p] ara tal função, é irrelevante se [a norma fundamental] provém de ato de pensamento, de ato de vontade, ou se é 'eine fingierte Norm' [uma norma fictícia] [...]"24.

O texto constitucional apenas produz norma válida porque há uma norma fundamental, pressuposta, não posta, que nos permite ter a interpretação do texto não mais num sentido subjetivo, mas num objetivo. Isso porque, "[c] como norma vale só o sentido de um ato de comando qualificado de certo modo, a saber: de um ato de comando autorizado pela norma de um ordenamento moral ou jurídico" 25 . Logo, todas as normas só são válidas porque buscam seu fundamento de validade, direta ou indiretamente, nas normas constitucionais. Essas, por sua vez, são obtidas do texto

\footnotetext{
${ }^{18}$ Estamos, aqui, desconsiderando o costume. De todo modo, “[d]aremos o texto da lei como seguramente estabelecido. [...]. E, dado o processo moderno de publicar as leis em colectâneas oficiais, também só muito excepcionalmente surgirão dificuldades na determinação do texto". Karl Engisch, Introdução ao pensamento jurídico, p. 128 (IV).

${ }^{19}$ Lourival Vilanova, Teoria jurídica da revolução: anotações à margem de Kelsen, Revista brasileira de estudos políticos, v. 52, p. 74 (itálicos constam do original).

20 "A polêmica concentra-se em quatro pontos: a necessidade, a possibilidade, o conteúdo e o status da norma fundamental". Robert Alexy, Conceito e validade do direito, p. 117 (3.III.1.1).

${ }^{21}$ Gottfried Leibniz, Novos ensaios sobre o entendimento humano, v. 2, p. 163-164 [IV.XII.6].

${ }^{22}$ Hans Kelsen, Teoría pural del derecho: introducción a los problemas de la ciencia jurídica, p .85 (V).

${ }^{23}$ BOBBIO põe o problema de ser o Direito um sistema nos seguintes termos: "[...] os principais problemas conexos com a existência de um ordenamento são os que nascem das relações das diversas normas entre si. Em primeiro lugar se trata de saber se essas normas constituem uma unidade [...]. O problema fundamental [...] é o da hierarquia das normas. [...]. Em segundo lugar trata-se de saber se o ordenamento jurídico constitui, além da unidade, também um sistema. O problema fundamental [...] é o das antinomias jurídicas. [...]. [Em terceiro lugar] Todo ordenamento jurídico, unitário e tendencialmente (se não efetivamente) sistemático, pretende também ser completo. O problema fundamental [...] é o das assim chamadas lacunas do Direito. [...]. Finalmente, não existe entre os homens um só ordenamento, mas muitos e de diversos tipos. [...]. O problema fundamental [...] é o do reenvio de um ordenamento a outro". Norberto Bobbio, Teoria do ordenamento jurídico, p. 34-35 (I.5) (itálicos constam do original).

${ }^{24}$ Lourival Vilanova, Causalidade e relação no direito, p. 56 (I.16) (esclarecemos e traduzimos entre colchetes).

${ }^{25}$ Hans Kelsen, Teoria geral das normas, p. 35 (8.IV).
}

Revista de Direito Brasileira | Florianópolis, SC | v. 28 | n. 11 | p.16-33 | Jan./Abr. 2021 
constitucional, o qual, por seu turno, é fonte do direito porque assim estabelece a norma fundamental.

\section{HOMOGENEIDADE SINTÁTICA DAS NORMAS JURÍDICAS}

As normas jurídicas são interpretações de texto e sua validade advém de outra norma jurídica. No entanto, resta, ainda, intocada a questão da estrutura dessas normas. Por estrutura, queremos aqui dizer o "[...] conjunto de elementos [...] e uma ou mais operações [...]" 26 . Logo, a estrutura da norma é a forma de ligação, por meio de operadores, de seus elementos, e se usarmos uma idiossincrasia semiótica, diremos que estamos no plano sintático, da sintaxe. Essa forma de ligação é, com efeito, o que podemos chamar de "[...] regras de formação, que determinam as combinações independentes permissíveis de membros do conjunto [...]"27. Há, no mais, as regras de transformação, mas vamos deixar isso para ser tratado mais à frente. Quanto às regras de formação em si, entendemos a norma jurídica numa estrutura única, bimembre, no formato de hipótese e consequência. Deixamos, com isso, de lado as normas categóricas, pois "[...] todas as normas gerais de um ordenamento positivo [...] podem prescrever uma certa conduta apenas sob condições bem determinadas" 28 .

De um texto, obtemos proposições, resultados do processo de significação. Proposições essas que devem ser ligadas, regra de formação, seguindo a estrutura hipótese/consequência. Nessa linha, "[...] a hipótese é descritiva de seu referente"29; já a consequência "[...] decompõe-se, internamente, numa relação, que, tecnicamente, denomina-se relação jurídica"30. Hipótese e consequência são, portanto, os elementos do conjunto norma. Essa é a razão de se falar em composição dual. Logo, "[p]or variado que seja estilisticamente, tecnicamente, idiomaticamente, o modo como o direito positivo de uma sociedade concreta se exprime, onde há regras [...], aí encontramos sua composição dual" 31 . Agora, uma vez fixada a forma bimembre, falta ainda o operador, aquilo que liga os elementos.

Se se dá certa situação (ação, omissão, evento da natureza), então deve-ser uma determinada conduta, a ser praticada por sujeito tal. Essa é a norma jurídica, ou melhor, sua estrutura; "[...] é a expressão da idéia de que algo deve ocorrer e, em especial, de que um indivíduo deve se conduzir de certa maneira" ${ }^{32}$. Estamos, com isso, diante do dever-ser. E, por essa linha, "[u]ma norma prescreve o que deve ser. Mas aquilo que deve ser não corresponde sempre ao que $e^{n 33}$. Há, nessa ideia, uma clara cisão do mundo da linguagem em prescrição e descrição. Por um lado, nas leis da natureza, ligamos a hipótese à consequência tendo em vista a causalidade. Linguagem descritiva do mundo. Por outro, no campo da normatividade, a hipótese é ligada à consequência pelo dever-ser. E, do dever-ser, podemos dizer que "[é] um conectivo operatório, ou partícula não referente a objetos ou a propriedade-de-objetos. É um functor" 34 .

E, para concluir este tópico, devemos fazer um breve comentário. Desde a crítica de Dworkin a Hart ${ }^{35}$, vem se discutindo o papel dos princípios no direito em uma linha que separa

\footnotetext{
${ }^{26}$ José Ferrater Mora, Dicionário de filosofia, verbete "estrutura", p. 233-234.

${ }^{27}$ Charles W. Morris, Fundamentos da teoria dos signos, p. 28 (III.1) (itálicos constam do original).

${ }^{28}$ Hans Kelsen, Teoria geral das normas, p. 27 (5).

${ }^{29}$ Lourival Vilanova, Causalidade e relação no direito, p. 78 (II.4) (itálicos constam do original).

${ }^{30}$ Lourival Vilanova, Causalidade e relação no direito, p. 78 (II.4). (itálicos constam do original).

${ }^{31}$ Lourival Vilanova, Estruturas lógicas e o sistema de direito positivo, p. 82 (III.7).

${ }^{32}$ Hans Kelsen, Teoria geral do direito e do estado, p. 51 (C.a.5).

${ }_{33}^{33}$ Norberto Bobbio, Teoria da norma jurídica, p. 152 (V.39) (itálicos constam do original).

${ }^{34}$ Lourival Vilanova, Lógica jurídica, p. 102 (III).

${ }^{35}$ HART, reconhecendo crítica de Dworkin, passou a aceitar a existência de princípios, sem com isso entender que deveria abandonar partes importantes de sua obra-prima, O conceito de direito: "Dworkin é credor de grande reconhecimento por ter mostrado e ilustrado a importância desses princípios [não conclusivos] e o respectivo papel no raciocínio jurídico, e, com certeza, eu cometi um sério erro ao não ter acentuado a eficácia não conclusiva deles. Mas também é seguro que não tencionava sustentar através do uso que fiz da palavra <<regra〉>, que os sistemas jurídicos Revista de Direito Brasileira | Florianópolis, SC | v. 28 | n. 11 | p.16-33 | Jan./Abr. 2021
} 
positivistas de não-positivistas. E uma forma dura de se conceber os princípios levaria a se afastar a ideia de homogeneidade sintática ${ }^{36}$. No entanto, neste trabalho, ficaremos com a ideia de que a questão dos princípios somente atinge o plano semântico e pragmático da norma jurídica. Por um lado, podemos ver um grau maior de indeterminação, de vagueza nos princípios, ou seja, uma maior abertura semântica. Por outro, na aplicação da norma tida como princípio, pode o utente querer vêla prevalecendo no caso concreto e individual, mesmo que tenha de afastar outra norma que se aplicaria de forma mais precisa. Mas, por qualquer dessas óticas, a questão sintática, e, portanto, da homogeneidade, fica intocada, sem que o tema dos princípios cinda as normas jurídicas de um ponto de vista estrutural.

\section{NORMA E SANÇÃO}

Atribui-se a Tales de Mileto a condição de primeiro filósofo. E o pensamento que ficou consagrado como filosófico foi o de que tudo tem uma natureza primeva (no caso, a água). No mais, a filosofia está presente porque se "[...] chega à consciência de que o um é a essência, o verdadeiro, o único que é em si e para si" ${ }^{37}$. E o mesmo pode ser dito do direito. Por mais variado que ele nos pareça, ele é norma jurídica e remota ao primeiro, à norma fundamental. Filosoficamente, esse é o direito, um conjunto de normas que tem origem no ponto comum, na norma fundante. Com isso, norma jurídica, no plano dinâmico, já sabermos o que é: uma norma que retira sua validade, ao fim e ao cabo, da norma fundamental. Mas, como também já dito, essa norma apresenta, plano estático, uma certa estrutura: hipotética-prescritiva; ou seja, há uma hipótese ligada a uma consequência por meio do dever-ser. No entanto, isso, per se, não dá conta de um traço que muitos grandes juristas atribuem ao direito, qual seja, a sanção ${ }^{38}$.

Em relação à sanção ser um traço característico do direito, temos dois pontos a opor: um é sobre a sua necessidade; outro diz respeito à sua possibilidade. Sintaticamente, a remissão à norma fundamental já é suficiente para dizermos que uma norma é direito, não sendo, portanto, necessário expor que essa norma é uma sanção ou que se liga à uma sanção (normas sancionadoras). Não há imperiosidade, assim, de se evocar a sanção para dizer o que é direito. Ademais, uma "[...] tal definição não mais pode ser dita formalista, porque define o conteúdo, objeto do direito"39. De outro lado, da possibilidade de afirmar que uma norma é uma sanção, diz muito, mas não diz tudo, já que há várias outras normas sancionadoras que não as normas jurídicas ${ }^{40}$. Assim, não é possível identificar a norma como jurídica por ser ela uma sanção ou ligada a uma sanção. De tudo, temos que a sanção não é necessária nem possível como traço distintivo do direito.

Ademais, há um problema grave para a definição de sanção e, por conseguinte, de norma sancionadora. O direito, como dito, prescreve conduta humana. E se essa conduta, a conduta prescrita, é causar um mal a outrem em razão de que esse outrem não praticou certa ação ou omitiu-

só contêm regras de <<tudo-ou-nada>> ou regras quase-conclusivas”. Herbert Hart, Pós-escrito, In: $\mathbf{O}$ conceito de direito, p. 325.

${ }^{36}$ A distinção entre regras e princípio seria “[...] uma distinção entre duas espécies de normas”. Robert Alexy, Teoria dos direitos fundamentais, p. 87 (3.I.1).

${ }^{37}$ Georg W. f. Hegel, Preleções sobre a história da filosofia, In: José Américo Mota Pessanha (consultor), Os présocráticos: vida e obra, p. 42.

${ }^{38}$ Por todos: "El derecho puede [...] definirse exactamente: el conjunto de normas según las cuales se ejerce en un Estado lá coacción”. Rudolf von Ihering, El fin en el derecho, p. 158 (VIII.10).

${ }^{39}$ Norberto Bobbio, O positivismo jurídico: lições de filosofia do direito, p. 159 (II.II.39).

${ }^{40}$ Expondo que os sistemas morais, portanto, não só o direito, possuem sanção, temos MILL: “O princípio da utilidade tem, ou não há qualquer razão para que não possa ter, todas as sanções que pertencem a qualquer outro sistema moral. Essas sanções são externas ou internas. [...]. São elas [as sanções externas] a esperança de receber benefícios e o receio de reprovação dos nossos semelhantes ou do Soberano do Universo [...]. [...]. A sanção interna do dever [...] - um sentimento na nossa própria mente, uma dor, mais ou menos intensa, concomitante da violação do dever [...]". John Stuart Mill, Utilitarismo, p. 132-133 (III).

Revista de Direito Brasileira | Florianópolis, SC | v. 28 | n. 11 | p.16-33 | Jan./Abr. 2021 
se quando isso era devido, então teríamos o que se denomina de sanção. A dificuldade reside, entretanto, na ideia de mal. Como saber se uma determinada ação que realizamos contra outrem é um mal? Intuitivamente, dentro do nosso senso comum, talvez não tenhamos dificuldades para responder tal pergunta. Mas basta um olhar mais apurado para vermos que as impressões não se sustentam. E isso sem aventarmos o sadismo e o masoquismo. É muito comum, por exemplo, que quem pratica a conduta não a veja como um mal, mas como, v.g., uma correção. Do lado de quem a sofre, por sua vez, pode ser vista essa mesma conduta como desnecessária, supérflua, frívola, ou seja, um mal.

O subjetivismo, portanto, não é o caminho. Não podemos, ao menos numa análise sintática do direito, imaginar que a pena "[...] deve representar, para aquele que irá sofrê-la, um sentimento de desagrado"41. E mesmo alguém da autoridade de KELSEN vê-se tentando a apelar à subjetividade para definir o ato coativo, pois afirma ser ele "[...] normalmente recebido pelo destinatário como um mal" ${ }^{\prime 2}$. Nessa linha, retribuir-se-ia as boas condutas com prazer (sanção premiada) e as más condutas com dor (sanção punitiva) ${ }^{43}$. Ocorre que enveredar por tal caminho significa se afastar da ideia de direito como um conjunto de normas encadeadas entre si, com uma origem comum, a norma fundamental, para graduar, no melhor estilo utilitarista, a dor e o prazer. Não se está, com isso, que fique claro, a negar que a pena tenha uma dupla função ${ }^{44}$, mas apenas se expondo que uma apresentação sintática do direito deve seguir por outra senda.

\section{NORMA PRIMÁRIA E NORMA EVENTUAL}

Dada certa situação, então deve-ser a conduta (ação ou omissão) devida. Assim, prescreve a norma, resultante de um texto. Em símbolos lógicos, temos: [(D) $p \rightarrow q$ ]; com toda norma tendo tal estrutura ${ }^{45}$. Entretanto, isso ainda não diz tudo quando estamos no plano jurídico, pois há, igualmente, outra norma, também extraída de texto, com validade buscada em norma superior, a qual prescreve: se não advir a conduta devida, então deve-ser, haja vista a eventualidade, uma outra conduta. Simbolizando, temos: $\left[(\mathrm{D}) \sim \mathrm{q} \rightarrow \mathrm{e}_{\mathrm{v}}\right.$ ]. Essa é a nossa proposta. Uma norma prescreve uma primeira conduta; por causa disso, vamos chamá-la de norma primária. Uma outra norma também prescreve uma conduta, mas só eventualmente, só se não se der a primeira conduta. Por isso, vamos chamá-la de norma eventual ${ }^{46}$.

Temos, assim, duas normas; mesma estrutura, mas diversas no conteúdo. Há, aqui, uma formalização, no sentido de abstrair-se a forma lógica. "E destaco, por abstração lógica, a forma desembaraçando-me da matéria que tal forma cobre" completa. Quando se diz que a norma é prescrição de conduta humana, por mais desprovido que seja isso de matéria, já se deixou o campo da lógica em seu sentido estrito. Com efeito, com essa demarcação, já temos dois tipos de proposição: as que tratam da conduta humana e as que não tratam. Distinção que não é meramente estrutural, mas também de conteúdo. Com isso, queremos dizer que um estudo sintático do direito já tem conteúdo, mesmo se o qualificarmos de mínimo.

\footnotetext{
${ }^{41}$ Ernst von Beling, A ação punível e a pena, p. 86 (II.I.2) (itálicos constam do original).

${ }^{42}$ Hans Kelsen, Teoria pura do direito, p. 35-36 (I.6.b).

43 “A pena, por sua força, é particularmente aplicável para prevenir as ações danosas e a única que é própria para impedir as que são extraordinariamente perniciosas. [...]. A recompensa, por sua força vivificante, é mais adequada para que se façam as ações úteis, e a única para que se executem as que são extraordinárias". Jeremias Bentham, As recompensas em matéria penal, p. 36-37 (6).

44 “Como coerção, a pena pode ter uma dupla natureza. a) Coerção indireta, mediata, psicológica, vale dizer criação dos motivos psicológicos ao agir. [...]. b) Coerção direta, imediata, mecânica, quer dizer, verdadeira e própria violência”. Franz von Liszt, A teoria finalística no direito penal, p. 43-44 (V) (itálicos constam do original).

${ }^{45}$ Estamos no plano estático da norma jurídica. Nesse plano, ela é uma prescrição hipotética. No entanto, sem nos dirigirmos ao plano dinâmico, não sabemos, apenas de posse da estrutura, se é uma norma jurídica. Somente será norma jurídica se retirar sua validade de outra norma jurídica.

46 Valterlei A. da Costa, Ensaio para uma teoria trilógica do tributo, p. 46.

${ }^{47}$ Lourival Vilanova, As estruturas lógicas e o sistema de direito positivo, p. 46 (I.6) (itálicos constam do original). Revista de Direito Brasileira | Florianópolis, SC | v. 28 | n. 11 | p.16-33 | Jan./Abr. 2021
} 
Agora, para-se nisso, pois um estudo sintático normativo não diz nada sobre a conduta regrada. Qualquer uma serve. E, especialmente, em relação à consequência da segunda norma, da eventual, não precisamos discutível se há ali a aplicação de uma dor ou de um prazer e como alguém disso se apercebe. Abre-se, assim, o guarda-chuva. Sob a denominação de eventualidade, cabe agora qualquer conteúdo para a conduta: pena, prêmio, inconstitucionalidade, ilegalidade, anulabilidade etc. Dito isso, podemos partir, então, para o estudo da norma jurídica completa.

KELSEN já havia concebido a estrutura completa da norma jurídica como (bi) bimembre. Contudo, em razão da primazia que sua Teoria Pura dá à sanção, resolveu chamar a norma que a contém de norma primária; a outra, de secundária ${ }^{48}$, chegando mesmo a afirmar que "[...] a norma 'Não matarás' é supérflua quando vigora uma norma que diz: 'Quem matar será punido' [...]"49. Nesse ponto, não andou bem o meridiano de Greenwich do direito. A não ser quando seja categórica, o que Kelsen chama de norma secundária, de forma alguma pode ser ela considerada supérflua, ao menos não no sentido de desnecessária. Afinal, não é qualquer $\sim q$ que implica a conduta $e_{v}$, mas apenas se antes de $\sim q$ tiver advindo $p$. Então, se sim, deve-ser $e_{v}$.

Mesmo em relação ao uso da expressão "norma primária" para a parte da norma completa que contém a sanção, há objeções a serem feitas à posição daquele que nasceu ainda sobre o Império Austro-húngaro. Parece que, in casu, Kelsen padeceu do mal que viu outros portando: um pensamento enviesado pela ideologia. Ambas as normas são importantes, pois sem uma parte, a outra não prevalece. Logicamente, a hipótese, a primeira conduta devida e a conduta eventual em caso de não realizada a primeira conduta devida têm o mesmo peso. A norma que possui a sanção não é, portanto, a mais importante, a primeira entre seus pares. Não tem, assim, nenhum caráter primus inter pares. No mais, “[a]s denominações adjetivas 'primária' e 'secundária' não exprimem relações de ordem temporal ou causal, mas de antecedente lógico para conseqüente lógico" $" 50$. Devemos, no entanto, ressalvar que KELSEN mudou de entendimento em relação à nomenclatura. Agora, "[o] muito que se divulgou no mundo com referência à norma primária e à secundária também não mais corresponde à última opinião de Kelsen" ${ }^{\text {51-52 }}$. Logo,

Se se admite que a distinção de uma norma que prescreve uma conduta determinada e de uma norma que prescreve uma sanção para o fato da violação da primeira seja essencial para o Direito, então precisa-se qualificar a primeira como norma primária e a segunda com secundária - e não o contrário, como o foi por mim anteriormente formulado ${ }^{53-54}$.

\footnotetext{
48 "La norma que establece la conducta que evita el acto coactivo, conducta que es la pretendida por el ordenamiento, tiene el significado de norma jurídica a condición de que com ella se diga - de forma abreviada, por comodidad expositiva - lo que tan solo la proposición jurídica (Rechtssataz) enuncia de manera correcta y completa, consistente en que en el supuesto de que se produzca la conducta contraria se ha de llevar a efecto el acto coactivo. Esta es la norma jurídica em su forma primaria. Por tanto, la norma que establece la conducta que evita el acto coactivo solo puede valer como norma secundaria”. Hans Kelsen, Teoría pura del derecho: introducción a los problemas de la ciencia jurídica, p. 60 (III.14.b).

${ }^{49}$ Hans Kelsen, Teoria pura do direito, p. 61 (I.6.e).

${ }^{50}$ Lourival Vilanova, Estruturas lógicas e o sistema de direito positivo, p. 105-106 (V.1).

${ }^{51}$ José Florentino Duarte, Palavras do tradutor, In: Hans Kelsen, Teoria geral das normas. p. IX.

${ }^{52}$ Kelsen ter modificado a nomenclatura, passando a chamar de primária a norma que antes chamava de secundária, não implica, necessariamente, qualquer mudança significativa em sua Teoria Pura, pois pode, sem qualquer contradição, entender que a sanção ainda é o traço distintivo do direito, mas que vem na norma que fica melhor designada de secundária.

${ }^{53}$ Hans Kelsen, Teoria geral das normas, p. 181 (35).

${ }^{54}$ Marcos Bernardes de Mello, com base na versão inglesa General theory of norms, p.142, Oxford: Clarendon Press, 1991, traduzida do alemão por Michael Hartney, chegou a um fim do excerto diverso: “[...] e não o contrário como expressei em capítulo anterior". Marcos Bernardes de Mello, Teoria do fato jurídico: plano da existência, p.65 (II.10.2.1). Uma outra tradução, a para o espanhol, feita por Hugo Carlos Delory Jacobs, leva-nos a dar razão a José Florentino Duarte: "Si se considera que para el derecho es esencial la distinción entre una norma que prescribe certa conducta, y otra norma que prescribe uma sanción para el caso de la violación da la primeira entonces se tiene que Revista de Direito Brasileira | Florianópolis, SC | v. 28 | n. 11 | p.16-33 | Jan./Abr. 2021
} 
Feitos esses esclarecimentos, resta a questão de saber como se ligam essas duas normas: a primária e a eventual ${ }^{55}$. Vamos, aqui, restringir-nos a duas possibilidades. Se unimos duas proposições com o conectivo conjuntivo $(\wedge)$, teremos uma proposição molecular verdadeira se

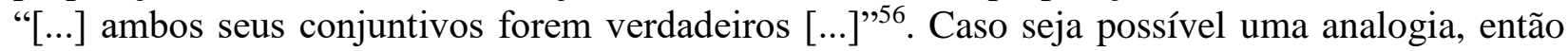
teremos uma norma válida apenas se a norma primária e a norma eventual forem ambas válidas. $\mathrm{O}$ cumprimento espontâneo do direito resta, nesse caso, inexplicado, afastado como não jurídico. Visando a evitar isso, vamos agora, neste trabalho, adotar uma posição mais fraca, ou seja, aquela que une as proposições por meio de uma disjunção inclusiva (v), ou seja, "[...] só é falsa no caso de ambos os disjuntivos serem falsos" ${ }^{" 57}$. COSSIO já tinha se dado conta disso ao unir a endonorma à perinorma, afirmando que "[1]a norma completa resulta, por lo tanto, um juicio lógicamente disyuntivo" 58 . Prosseguindo com essa linha, vamos tomar como fecho deste tópico, se não nosso maior jurista, sem dúvidas, um dos maiores: "O esquema da norma jurídica toma a forma 'deve ser que se $\mathrm{H}$, então $\mathrm{C}$ ', ou ' $\mathrm{D}(\mathrm{H} \rightarrow \mathrm{C})$ '. Abrangendo a norma primária e a norma secundária [nossa norma eventual], temos ' $\mathrm{D}[(\mathrm{H} \rightarrow \mathrm{C}) v($ não- $\mathrm{C} \rightarrow \mathrm{E})]$ '",59.

\section{NORMA DE CONDUTA E NORMA DE COMPETÊNCIA}

O direito é um modo de prescrever a conduta humana. Qualquer conduta. Pode até ser verdade que a "[...] a felicidade dos indivíduos de que se compõe uma comunidade [...] constitui o objetivo, o único objetivo que o legislador deve ter em vista [...]"60, mas uma norma jurídica retira sua validade de outra norma jurídica e não da função que exerce para a felicidade de todos. Que bem se legisle, isso é um desejo de todos, mas não é a fonte de validade da norma jurídica. Assim, qualquer conduta humana pode ser prescrita e a validade da norma jurídica que prescreve essa conduta não depende de seu conteúdo em si.

Do fato, entretanto, de que qualquer conduta pode ser prescrita, não decorre que não possam ser classificadas as normas em razão do que se prescreve. Há, nessa ideia, um abrandamento de uma sintaxe pura. Num primeiro momento, já fizemos um corte: a consequência da norma, quer da primária, quer da eventual, é uma conduta humana. Num segundo momento, podemos classificar essas condutas devidas. E se falarmos apenas das condutas contidas na consequência da norma primária, então podemos dizer que um dos mais conhecidos modos de se classificar as normas é como: de conduta e de competência. Com efeito, ensina-nos ROSS:

As normas jurídicas podem ser divididas, de acordo com seu conteúdo imediato, em dois grupos: normas de conduta e normas de competência. Ao primeiro grupo pertencem as normas que prescrevem uma certa linha de ação [...]. O segundo grupo contém as normas que criam uma competência (poder, autoridade) - são diretivas que dispõem que as normas que são criadas em conformidade com um modo estabelecido de procedimento serão consideradas como normas de conduta $^{61}$.

\footnotetext{
caracterizar la primeira como norma primaria y la segunda como norma secundaria - y no a inversa, como fue formulado por mí em las argumentaciones precedentes”. Hans Kelsen, Teoría general de las normas, p. 148.

${ }^{55}$ As opções são: “[...] e, ou-(ou-includente), 'se ..., então' [...]. Exclui-se [...] 'ou-disjuntivo', pois este conectivo exclui a verdade ou a validade simultânea dos dois membros". Lourival Vilanova, As estruturas lógicas e o sistema do direito positivo, p. 120 (V.12) (itálicos constam do original).

${ }^{56}$ Irving Copi, Introdução à lógica, p. 227 (II.8.II).

${ }^{57}$ Irving Copi, Introdução à lógica, p. 230 (II.8.II).

${ }^{58}$ Carlos Cossio, Teoría de la verdad jurídica, p. 122 (IV.2).

${ }^{59}$ Lourival Vilanova, Causalidade e relação no direito, p. 94 (II.12).

${ }^{60}$ Jeremy Bentham, Uma introdução aos princípios da moral e da legislação, p. 14 (III).

${ }^{61}$ Alf Ross, Direito e justiça, p. 57 (II.7).
}

Revista de Direito Brasileira | Florianópolis, SC | v. 28 | n. 11 | p.16-33 | Jan./Abr. 2021 
Esse mesmo modo de classificar está presente, igualmente, em outros grandes juristas, com nomenclatura um pouco diversa. HART fala de norma primária e de norma secundária ${ }^{62}$. BOBBIO, que inicialmente valeu-se da expressão norma de estrutura ${ }^{63}$, profere normas de organização ao lado de normas de conduta ${ }^{64}$. Variedade à parte da terminologia, de certo, temos uma classificação da norma primária, gênero, em duas espécies, a depender da conduta regrada: a conduta que produz normas e as demais condutas ${ }^{65}$. O direito, como linguagem, ganha, assim, sua regra de transformação ${ }^{66}$.

Um texto T é posto. Desse texto é obtida uma significação, a norma N. Essa significação pode estabelecer o dever-ser de conduta de alguém $\left(\mathrm{S}_{1}\right)$, ou seja, $q$. Ainda se pode dar que o deverser apenas se verifique diante da ocorrência de uma situação prévia, de um ser, ou seja, $p$. Nesse caso, diz-se que a prescrição é hipotética. Pode, igualmente, advir desse texto T um dever de conduta eventual, em face da norma eventual $\mathrm{Ne}_{\mathrm{v}}$, para outrem $\left(\mathrm{S}_{2}\right)$, e dizemos eventual porque apenas surge diante da não-ocorrência da primeira conduta devida, ou seja, $\sim q$. Dá-se, então, a norma completa $\mathrm{Nc}^{67}$.

Mas tal estrutura sintática ainda não nos diz se estamos diante de uma norma jurídica, pois somente no plano dinâmico é isso possível. Assim, tem-se uma norma jurídica Nc se presente uma outra norma jurídica, na verdade, uma sobrenorma $\mathrm{sN}$, que trate da forma de pôr o texto $\mathrm{T}$, prescrevendo, igualmente, que seu sentido subjetivo é também o sentido objetivo. A essa norma SN é que denominamos, com ROSS, de norma de competência. E como já dissemos que a norma de competência é assim classificada em razão de seu conteúdo, não de sua forma, de sua estrutura, e se lembrarmos da homogeneidade sintática, então a norma de competência é apenas uma parte de uma sobrenorma jurídica completa, ou seja, é norma primária. Há a necessidade, portanto, de verificarmos a norma eventual que se liga a essa norma primária para obter a norma jurídica de competência completa.

Uma sN prescreve: dada certa situação $p$ (hipótese), mediante determinada forma, é permitido ao sujeito $\mathrm{S}_{1}$ pôr o texto $\mathrm{T}$-mediante a conduta $q$ (consequência), a qual se pode chamar de ação normativa ${ }^{68}$ - que deve-ser interpretado como norma jurídica N. Pode ser, ainda, estabelecido por $\mathrm{sN}$, de forma mais ou menos genérica, o conteúdo de $\mathrm{N}$, mas lembrando que "[m] esmo uma ordem o mais pormenorizada possível tem de deixar àquele que a cumpre ou

\footnotetext{
62 "Por força das regras de um tipo, que bem pode ser considerado o tipo básico ou primário, aos seres humanos é exigido que façam ou se abstenham de fazer certas acções, quer queiram ou não. As regras do outro tipo são em certo sentido parasitas ou secundárias em relação às primeiras: porque asseguram que os seres humanos possam criar, ao fazer ou dizer certas coisas, novas regras do tipo primário, extinguir ou modificar as regras antigas, ou determinar de diferentes modos sua incidência ou fiscalizar a sua aplicação. As regras do primeiro tipo impõem deveres, as regras do segundo tipo atribuem poderes, públicos ou privados". Herbert Hart, O conceito de direito, p. 91 (V.1).

63 "Existem normas de comportamento ao lado de normas de estrutura". Norberto Bobbio, Teoria do ordenamento jurídico, p. 45 (2.3).

64 "São normas de conduta as que, limitando a própria obra à coordenação de ações individuais, estabelecem as condições para obter o máximo de independência dos indivíduos que convivem entre si. São normas de organização as que, mediante um trabalho de convergência (forçada) de ações sociais, estabelecem as condições para proporcionar o mínimo de dependência necessário a indivíduos que cooperam entre". Norberto Bobbio, Da estrutura à função (6), p. 121.

${ }^{65}$ Quer com o nome de norma de competência, de estrutura ou de organização, o certo é que ela é " [...] uma norma de conduta expressa indiretamente". Alf Ross, Direito e justiça, p.57 (II.7). Ou seja, "[e]las não regulam o comportamento, mas o modo de regular um comportamento, ou, mais exatamente, o comportamento que elas regulam é o de produzir regras". Norberto Bobbio, Teoria do ordenamento jurídico, p. 45 (2.3).

66 “[...] regras de transformação, que determinam as frases que podem ser obtidas de outras frases”. Charles W. Morris, Fundamentos da teoria dos signos, p. 28 (III.1) (itálicos constam do original).

${ }^{67}$ Estamos aqui simplificando, uma norma completa pode ser formada a partir de vários textos, dispersos por vários documentos.

68 "Para el modo peculiar de la acción, que tiene como resultado la existencia de prescripciones, acuñamos el nombre acción normativa". Georg von Wright, Norma y acción: una investigación lógica, p. 91-92 (V.7).
}

Revista de Direito Brasileira | Florianópolis, SC | v. 28 | n. 11 | p.16-33 | Jan./Abr. 2021 
executa uma pluralidade de determinações a fazer" ${ }^{69}$. E esse conteúdo pode ser fixado de forma positiva ou negativa, sendo, na maioria das vezes, ambas as formas usadas. Nesse caso, a significação de $\mathrm{sN}$ para que se possa produzir $\mathrm{N}$ somente é alcançada por meio de um processo que considere esta (negativa) e aquela (positiva) formas de demarcação. Com isso, temos a norma primária da norma de competência.

Entretanto, pode ser que quando posta $\mathrm{N}$ não havia ocorrida a hipótese, ou que não foi respeitada a forma ou, mesmo, que não tenha o conteúdo escorreito, nos termos de $\mathrm{sN}$. O que vamos, aqui, com fins de simplificação, chamar de $\sim q$. Então deve-ser, da parte de $\mathrm{S}_{2}$, a conduta eventual $e_{v}$, conduta de invalidação da norma jurídica $\mathrm{N}$ assentada. Invalidação essa que, por sua vez, pode assumir os mais variados nomes, a depender do tipo de norma que se invalide: inconstitucionalidade, ilegalidade, anulabilidade etc. Todavia, se quisermos um nome amplo, podemos denominar essa conduta eventual $e_{v}$ de invalidação de conduta de garantia:

Na sua essência, a garantia repousa (embora não se esgote) num juízo de conformidade ou desconformidade perante a norma garantida; procura-se saber se um acto ou uma norma de grau inferior são conformes ou desconformes com uma norma de grau superior e, no caso de desconformes, procura-se inutilizá-las ${ }^{70}$.

Portanto, a conduta de garantia seria uma espécie do gênero conduta eventual. Com isso, agora temos: na norma primária, um mínimo semântico, a conduta é de a pôr norma jurídica; por sua vez, na norma eventual, outra dose de conteúdo, a conduta é a de invalidação ou de garantia.

Com síntese, podemos apresentar a estrutura completa da norma de competência, com conteúdo semântico mínimo: em determinadas circunstâncias, sob certa forma, é permitido pôr (conduta) um texto, com adequado conteúdo, cuja significação deve-ser tida como uma norma jurídica, ou, não sendo o prescrito seguido ao estatuir a norma jurídica, então deve-ser obrigatória a conduta de garantia que invalide a norma jurídica que foi posta em desconformidade.

\section{EMENDA CONSTITUCIONAL: DESAMBIGUAÇÃO}

De um texto $\mathrm{T}_{1}$, obtém-se a norma $\mathrm{N}_{1}$. De um texto $\mathrm{T}_{2}$, logra-se a $\mathrm{N}_{2}$. Pode ocorrer que $\mathrm{N}_{1}$ prescreva que se $p$, então deve-ser $q$. Pode, ainda, ser o caso de $\mathrm{N}_{2}$ normatizar que sendo $p$, então deve-ser $\sim q$. Não é possível, só com esses dados, saber se diante de $p$, qual o dever-ser, se $q$ ou $\sim q$. Há, assim, a necessidade de uma outra norma para se conhecer qual a conduta devida. E já vimos ser possível norma que estabelece que o texto posto por último é o que produz a norma válida, a qual chamamos de $\mathrm{N}_{3}$. Mas vamos, agora, tratar de uma outra hipótese, outra norma $\mathrm{N}_{4}$, fruto de texto $\mathrm{T}_{4}$, que soluciona o caso de modo diverso de $\mathrm{N}_{3}$, estabelecendo que havendo conflito entre $\mathrm{N}_{1}$ e $\mathrm{N}_{2}$, então deve-ser válida a conduta prescrita pela norma de superior hierarquia. Ou seja, lex superior derrogat inferiori ${ }^{71}$.

Essa é a situação que se aplica a Ulisses. Sua primeira ordem, amarrem-me, deve prevalecer frente à segunda ordem, desamarrem-me, porque há uma norma que estabelece a superioridade da primeira ordem sobre a segunda. Logo, uma ordem, mesmo que posterior, não pode tomar o lugar de uma ordem anterior porque há uma outra que fixa, na linha da hierarquia, a superioridade da primeira. As ordens são endereçadas aos marinheiros. E esses devem respeitar a primeira ordem de Ulisses e não a segunda em razão de uma norma que assim dispõe. Agora, se é

\footnotetext{
${ }^{69}$ Hans Kelsen, Teoria pura do direito, p. 388 (VIII.1.a).

${ }^{70}$ Jorge Miranda, Contributo para uma teoria da inconstitucionalidade, p. 212 (III.A.106).

${ }^{71}$ Mas e se existir tanto $\mathrm{N}_{3}$ como $\mathrm{N}_{4}$ ? Qual delas deve ser a utilizada para resolver o conflito? Com efeito, "[a]o lado do conflito entre as normas, que dá lugar ao problema das antinomias, há o conflito dos critérios para a solução das antinomias, que dá lugar a uma antinomia de segundo grau". Norberto Bobbio, Teoria do ordenamento jurídico, p. 107 (3.7). Não temos dúvidas de que apenas a vontade, pondo uma outra norma $\mathrm{N}_{5}$, é que pode dar tal resposta.
} 
o rei de Ítaca quem põe essa norma, a de hierarquia, então só assim podemos imaginar Ulisses se autolimitando.

Transferindo essa história para a Constituição de 1988, temos que o texto constitucional produz uma quantidade de normas. Texto posto por quem comumente chamamos de poder constituinte originário, assim tido em razão da norma fundamental. E dentro dessa quantidade de normas decorrentes do texto posto, há aquelas de competência que permitem pôr outras normas (art. 59 da $\mathrm{CF} / 88$ ) e, mais especificamente, as que permitem mudanças no texto da Constituição (art. 59, I, da CF/88). Com isso, podem aqueles que denominamos de poder constituinte derivado, em razão da Constituição, respeitando a forma prescrita (art. 60 da CF/88), pôr um texto que deve ser lido como norma válida mesmo que contrário ao texto primevo. Lex posterior derogat priori. Entretanto, assim não se dá em casos de abolição: da forma federativa do Estado; do voto direito, secreto, universal e periódico; da separação dos Poderes; e dos direito e garantias individuais (art. $\left.60, \S 4^{\circ}\right)$. Nesses casos, o que prevalece é lex superior derrogat inferiori.

Dito isso, fica fácil não incorrer naquele vício de designar, sem maiores cuidados, pelo mesmo nome, tanto o processo como o produto. Com efeito, "emenda constitucional" é expressão ambígua que tanto pode se referir à norma de competência prevista na Constituição como ao produto resultante do uso dessa norma de competência, ou seja, outra norma, que, por sua vez, tanto pode ser de competência como de conduta.

Temos até agora 99 emendas à Constituição ${ }^{72}$. Esses são textos produzidos pelo legislador constituinte derivado que nos dão normas válidas ou, melhor dizendo, fragmentos de normas, porque se ancoram, seu sentido subjetivo adquire caráter de sentido objetivo, na norma de competência constitucional que traz a regra de transformação. Não há, assim, um porquê confundir, por um lado, emenda constitucional como norma de competência que autoriza pôr norma e, por outro, seu produto, a norma posta, apesar de que está última também é chamada de emenda constitucional.

\section{AS CLÁUSULAS PÉTREAS E A NORMA DE (IN) COMPETÊNCIA}

O legislador constituinte originário não se autorregula, não se autolimita. O que, de fato, faz é pôr norma limitando o constituinte derivado. Com isso, "[e]l poder de reforma constitucional es - como todo poder constituido - un poder limitado, circunscrito por las normas que lo regulan"73. Logo, por tudo que vimos até agora, há uma prescrição hipotética (emenda constitucional) que permite pôr texto (também chamado de emenda constitucional), assumindo o lugar de outro texto constitucional com ele contraditório, o qual resta excluído. Essa é a norma primária da norma de competência completa.

Mas esse permitido pôr não se dá de forma plena. Há limites. O primeiro é em relação à hipótese da norma de competência primária, pois apenas é permitido pôr nova norma constitucional, por meio de um texto, se não estiver vigendo intervenção federal, estado de defesa ou estado de sítio (art. 60, $\S 1^{\circ}$, da CF/88). Já na consequência, quanto à forma da ação normativa, deve ser a proposta de emenda - que pode ser apresentada por um terço, no mínimo, dos membros da Câmara dos Deputados e ou do Senado Federal; do Presidente da República; ou de mais da metade das assembleias legislativas das unidades da federação, manifestando-se, cada uma delas, pela maioria relativa de seus membros (art. 60, I, II e III, da CF/88) — discutida e votada em cada casa do Congresso Nacional, em dois turnos, considerando-se aprovada se obtiver, em ambos, três quintos dos votos dos respectivos membros (art. 60, $\S 2^{\circ}$, da CF/88). E, outrossim, na consequência, quanto ao texto em si a ser posto, sem tratarmos aqui de eventuais pontos implícitos, optou o legislador expressamente por regulá-lo negativamente, o que nos permite falar de norma de incompetência. Com efeito, é proibido emendar a Constituição para abolir: a forma federativa do

\footnotetext{
${ }^{72}$ As 6 emendas de revisão foram produzidas seguindo um rito próprio (art. $3^{\circ}$ da ADCT).

${ }^{73}$ Riccardo Guastini, Interpretar y argumentar, p.319-320 (IV.III.1)
}

Revista de Direito Brasileira | Florianópolis, SC | v. 28 | n. 11 | p.16-33 | Jan./Abr. 2021 
Estado; o voto direito, secreto, universal e periódico; a separação dos Poderes; e os direito e garantias individuais (art. 60, $\S 4^{\circ}$, da $\mathrm{CF} / 88$ ).

Com isso, a princípio, temos a norma de competência que permite emendar a Constituição. Agora, a norma de competência, como norma jurídica que é, forma-se de duas partes. A primária, a qual acabamos de descrever, dispondo sobre a ação normativa para emendar a Constituição, e a eventual, sendo, para o caso, sua espécie, a norma de garantia. Nessa segunda parte da norma completa, temos, como hipótese, o descumprimento da norma primária:

Uma lei de alteração da Constituição [...] pode infringir, formal ou materialmente, disposições da Constituição formal. Dá-se o primeiro caso, quando não são observadas as disposições processuais prescritas para alteração da Constituição; ocorre o último, quando uma lei se propõe alterar disposições da Constituição contrariamente à declaração da imodificabilidade destas inserta no documento constitucional $[\ldots]^{74}$.

E, como consequência, temos, aplicada na eventualidade de descumprimento da primeira norma, à guisa de garantia, a declaração de inconstitucionalidade da norma posta pela emenda constitucional, quando, então, deparar-nos-emos com o que se convencionou chamar de norma constitucional inconstitucional.

\section{CONCLUSÃO}

Ao fim e ao cabo, tudo bem pesado e sopesado, vemos que as cláusulas pétreas não são, no sentido estrito, normas jurídicas. São, isso sim, fragmentos de norma contidos no texto constitucional, especificamente alocados na consequência da norma primária da norma de competência completa. E atuam determinando negativamente a conduta do legislador constituinte derivado - e só nesse sentido podem ser ditas como norma de incompetência —, o qual fica condicionado ao pôr o texto da emenda; ainda restando, caso não respeitadas as cláusulas pétreas, agora para o guardião da Constituição, o dever-ser de conduta eventual ou, no caso, de garantia, com a consequente inconstitucionalidade da norma posta em desconformidade.

\section{REFERÊNCIAS}

ABBAGNANO, Nicola. Dicionário de filosofia. Tradução da 1.ed. brasileira coordenada e revista por Alfredo Bosi; revisão da tradução e tradução dos novos textos Ivone Castilho Benedetti. 4.ed. São Paulo: Martins Fontes, 2000.

ALEXY, Robert. Conceito e validade do direito. Tradução de: Gercélia Batista de Oliveira Mendes. São Paulo: WMF Martins Fontes, 2009.

. Teoria dos direitos fundamentais. Tradução de: Virgílio Afonso da Silva. 2.ed. São

Paulo: Malheiros, 2011.

BACHOF, Otto. Normas constitucionais inconstitucionais? Tradução de: José Manuel M. Cardoso da Costa. [S.1]: Atlântida, [1977?].

BARTHES, Roland. Elementos de semiologia. Tradução de: Izidoro Blikstein. 16.ed. São Paulo: Cultrix, 2006.

${ }^{74}$ Otto Bachof, Normas constitucionais inconstitucionais?, p.52 (IV.1.b) (itálicos constam do original). Revista de Direito Brasileira | Florianópolis, SC | v. 28 | n. 11 | p.16-33 | Jan./Abr. 2021 
BELING, Ernst von. A ação punível e a pena. Tradução de: Maria Carbajal. São Paulo: Rideel, 2007.

BENTHAM, Jeremy. As recompensas em matéria penal. Tradução de: Thais Miremis Sanfelippo da Silva Amadio. São Paulo: Rideel, 2007.

. Uma introdução aos princípios da moral e da legislação. Tradução de: Luiz João

Baraúna. 2.ed. São Paulo: Abril Cultura, 1979.

BOBBIO, Norberto. Da estrutura à função. Tradução de: Daniela Beccaccia Versiani. Barueri, SP: Manole, 2007.

O positivismo jurídico: lições de filosofia do direito. Tradução de: Márcio Pugliesi, Edson Bini e Carlos E. Rodrigues. São Paulo: Ícone, 2006.

. Teoria da norma jurídica. Tradução de: Fernando Pavan Baptista e Ariani Bueno Sudatti. 2.ed. Bauru, SP: EDIPRO, 2003.

Teoria do ordenamento jurídico. Tradução de: Maria Celeste C. J. Santos. 10.ed.

Brasília: Universidade de Brasília, 1999.

BULFINCH, Thomas. O livro de ouro da mitologia: história de deuses e heróis. Tradução de:

David Jardim Júnior. 25.ed. Rio de Janeiro: Ediouro, 2001.

BUYSSENS, Eric. Semiologia e comunicação linguística. Tradução de Izidoro Blikstein. São Paulo: Cultrix, Ed. da Univerdidade de São Paulo, 1972.

COELHO NETTO, J. Teixeira. Semiótica, informação e comunicação. São Paulo: Perspectiva, 2003.

COPI, Irving Marmer. Introdução à lógica. Tradução de: Álvaro Cabral. 2.ed. São Paulo: Mestre Jou, 1978.

COSSIO, Carlos. Teoría de la verdade jurídica. Buenos Aires: El foro, 2007.

COSTA, Valterlei A. da. Ensaio para uma teoria trilógica do tributo: um estudo normativo sobre tributação, competência e lançamento. 2019. 248f. Dissertação (Mestrado em Direito) — UFPR, Curitiba.

DUARTE, José Florentino. Palavras do tradutor. In: KELSEN, Hans. Teoria geral das normas. Tradução de: José Florentino Duarte. Porto Alegre: Sérgio A. Fabris, Editor, 1986.

ELSTER, Jon. Ulisses liberto: estudos sobre a racionalidade, pré-compromisso e restrições.

Tradução de: Cláudia Sant'Ana Martins. São Paulo: UNESP, 2009.

ENGISCH, Karl. Introdução ao pensamento jurídico. Tradução de: J. Baptista Machado. 7.ed. Lisboa: Calouste Gulbenkian, 1996. 
GUASTINI, Riccardo. Interpretar y argumentar. Traducción de: Silvina Álvares Medina. Madrid: Centro de Estudios Políticos y Constitucionales, 2014.

GUIBOURG, Ricardo A. El fenómeno normativo: acción, norma y sistema, la revolución informática, niveles del análisis jurídico. Buenos Aires: Astrea, 1987.

HART, Herbert L. A. O conceito de direito. Tradução de: A. Ribeiro Mendes. 4.ed. Lisboa: Calouste Gulbenkian, 2005.

HAYEK, Friedrich A. The constitution of liberty. Chicago: University of Chicago Press, 1960.

HEGEL, Georg Wilhelm Friedrich. Preleções sobre a história da filosofia. In: PESSANHA, José Américo Mota (consultor). Os pré-socráticos: vida e obra. Tradução de: Ernildo Stein. São Paulo: Nova Cultura, 2000.

HEGENBERG, Leonidas. Dicionário de lógica. São Paulo: EPU, 1995.

HJELMSLEV, Louis. Prolegômenos a uma teoria da linguagem. Tradução de: J. Teixeira Coelho Netto. São Paulo: Perspectiva, 2003.

HUME, David. Investigações sobre o entendimento humano e sobre os princípios da moral. Tradução de: José Oscar de Almeida Marques. São Paulo: UNESP, 2004.

Tratado da natureza humana: uma tentativa de introduzir o método experimental de raciocínio nos assuntos morais. Tradução de: Débora Danowski. 2.ed. São Paulo: UNESP, 2009.

IHERING, Rudolf von. El fin en el derecho. Buenos Aires: Atalaya, 1946.

KELSEN, Hans. Manuscrito direito e lógica (9.6.1965). In: KELSEN, Hans; KLUG, Ulrich. Normas jurídicas e análise lógica [correspondência trocada entre os Srs. Hans Kelsen e Ulrich Klug]. Tradução de Paulo Bonavides. Rio de Janeiro: Forense, 1984.

1994.

Teoría general de las normas. Traductor: Hugo Carlos Deloy Jacobs. México: Trillas,

. Teoria geral das normas. Tradução de: José Florentino Duarte. Porto Alegre: Sérgio A. Fabris, Editor, 1986.

. Teoria geral do direito e do estado. Tradução de: Luís Carlos Borges. 4.ed. São Paulo: Martins Fontes, 2005.

Teoría pura del derecho: introducción a los problemas de la ciência jurídica Traducción de: Gregorio Robles Morchón y Felix F. Sánchez. Madrid: Trotta, 2011 (primeira edición de 1934).

Teoria pura do direito. Tradução de: João Baptista Machado. 6.ed. São Paulo: Martins Fontes, 1998 (segunda edição de 1960). 
LARENZ, Karl. Metodologia da ciência do direito. Tradução de: José Lamego. 3.ed. Lisboa: Calouste Gulbenkian, 1997.

LEIBNIZ, Gottfried Wilhelm. Novos ensaios sobre o entendimento humano. Vol. 2. Tradução de: Luiz João Baraúna e Carlos Lopes de Mattos. São Paulo: Nova Cultural, 1988.

LISZT, Franz von. A teoria finalista no direito penal. Tradução de: Rolando Maria da Luz. Campinas, SP: LZN, 2003.

MELLO, Marcos Bernardes de. Fato jurídico: plano da existência. 18.ed. São Paulo: Saraiva, 2012.

MILL, John Stuart. Utilitarismo. Tradução de: Ricardo Marcelino Palo Rodrigues. São Paulo: Hunter Books, 2014.

MIRANDA, Jorge. Contributo para uma teoria da inconstitucionalidade. [S.1.]: Coimbra Editora, 1996.

MORA, José Ferrater. Dicionário de filosofia. Tradução de: Roberto Leal Ferreira e Álvaro Cabral. São Paulo: Martins Fontes, 2001.

MORRIS, Charles W. Fundamentos da teoria dos signos. Tradução de: Milton José Pinto. São Paulo: Ed. da Universidade de São Paulo, 1976.

PERELMAN, Chaïm. OLBRECHTS-TYTECA, Lucie. Tratado da argumentação: a nova retórica. Tradução de: Maria Ermantina de Almeida Prado Galvão. 2.ed. São Paulo: Martins Fontes, 2005.

ROSS, Alf. Direito e justiça. Tradução de: Edson Bini. Bauru, SP: Edipro, 2003.

SAUSSURE, Ferdinand. Curso de lingüística geral. Tradução de: Antonio Chelini, José Paulo Paes e Izidoro Blikstein. 25.ed. São Paulo: Cultrix, 2003.

VILANOVA, Lourival. As Estruturas lógicas e o sistema de direito positivo. 3.ed. São Paulo: Noeses, 2005.

. Casualidade e relação no direito. 4.ed. São Paulo: Revista dos Tribunais, 2000.

. Lógica jurídica. São Paulo: Bushatsky, 1976.

. Teoria jurídica da revolução (anotações à margem de Kelsen). Revista brasileira de estudos políticos, v. 52. Belo Horizonte: UFMG, p. 59-103, 1981.

WRIGHT, Georg Henrik von. Norma y acción: una investigación lógica. Traducción de: Pedro Garcia Ferrero. Madrid: Editorial Tecnos, 1970. 